Hastings, A., Bailey, N., Gannon, M., Besemer, K., \& Bramley, G. (2015). Coping with the Cuts? The Management of the Worst Financial Settlement in Living Memory. Local Government Studies, 1-21.

doi:10.1080/03003930.2015.1036987

\title{
Coping with the Cuts? The Management of the Worst Financial Settlement in Living Memory
}

\begin{abstract}
The scale of the cuts to local government finance, coupled with increasing demand for services, has led to unprecedented 'budget gaps' in council budgets. Arguably, two competing narratives of the trajectory of local government have emerged in which contrasting futures are imagined for the sector - a positive story of adaptation and survival and more negative one of residualisation and marginalisation. Drawing on case study evidence from three English local authorities, the paper distinguishes and provides examples of three strategic approaches to managing austerity efficiency, retrenchment and investment. It demonstrates how and why the balance of these strategies has shifted between the early and later phases of austerity and considers the extent to which the evidence of the case studies provide support for either the survival or marginalisation narrative. The paper concludes by arguing that a third narrative - responsibilisation - captures more fully the trajectory of local government in England.
\end{abstract}

Key Words: austerity, coalition, poor communities, localism

Introduction

It is well known that local government is one of the foremost casualties of the fiscal austerity which has characterised UK public policy since the 2010 Comprehensive Spending Review (see Bailey, Bramley, and Hastings 2015, this issue). The sector in England has been particularly badly hit - the 2010 Settlement resulted in a reduction of revenue grant of $£ 5.6$ billion over the 4- year period of the review, a cash cut of $28 \%$ which translates to a real terms cut of $40 \%$. This level of revenue cut was mirrored by a reduction in capital grant averaging around $40 \%$ over the same four years (Hastings et al. 2012). In June 2013, a Spending Review for one further year (2015/2016) indicated that the budget for local government would be reduced by a further $10 \%$ (Hastings et al. 2013b). These top-level cuts are in addition to a range of other far-reaching measures which impact on the fiscal climate in which local government operates - such as the localisation of, and cuts to, council tax benefit as well as the capacity for councils to retain a proportion of income generated from business rates. There is also particular concern that the cuts impact disproportionately on the most deprived cities and authorities, an issue which is discussed in detail in Bailey et al. (2015). Indeed, local government is probably a critical case of what Peter Taylor-Gooby (2013) calls the 'double crisis of the welfare state'. This 'double whammy' is essentially the interaction of fiscal austerity with increased pressures on services resulting from socio-demographic change, such as the ageing profile of the population, as well as recessionary impacts on jobs and impacts (ibid., 5-10). It appears to confirm Donald et al.'s observation that 'state resources tend to decline just when needs increase' $(2014,6)$ As a consequence, many local authorities (LAs) in England are dealing with unprecedented 'budget gaps' - that is, a massive shortfall in resources resultant from the combination of funding reductions and cost pressures. This paper explores how English LAs are attempting to close these gaps in resource needs, with a focus on the strategies of three case study councils. These strategies are explored in relation to two contrasting narratives apparent in debate about the future trajectory of local government in response to this crisis - the narratives of survival and marginalisation. The 
literature review which forms the second section of the paper establishes these narratives. A third section provides details of the research design used to assess the strategies of the case studies. It introduces an analytical framework derived from the bigger project of which this paper is part.1 The fourth part of the paper reports the evidence from the case studies in relation both to the project's analytical framework and the contrasting narratives evident in the wider literature. The paper concludes by considering whether a third narrative - responsibilisation - captures more fully the trajectory of local government in England. Literature review Writing in 2012, Gerry Stoker distinguished two potential scenarios for the future of local government. One was largely positive and emphasised the potential of budgetary constraint to drive innovation and diversity. The second was negative, characterised by a 'dynamic of public service decay' (Stoker 2012, 15). Since then, commentary on the implications of austerity continues to be framed in both positive and negative terms, to the extent that it is increasingly possible to discern two relatively coherent and contrasting storylines or narratives. The first of these emphasises the capacity of local government to adjust to and survive periods of austerity, both historic and contemporary. For example, John (2014) describes how the sector has 'weathered successive crises (which) demonstrates its persistence, resilience and an instinct for survival rather than vulnerability to external forces' (688). He argues that the development of a strong 'centre of power' has allowed local government to withstand change in the 'outer organisation ... (which) can be sacrificed without threatening the identity and salience of the primary organisation' (692). John's account resonates with that of Shaw (2012) in which the resilience of local government and its adaptive capacity are highlighted, as well as with a number of accounts which foreground how austerity can facilitate innovation and creativity (Bunt, Harris, and Westlake 2010; Lowndes and McCaughie 2013). Within this narrative, there is some recognition that the Coalition Government's localism agenda affords new freedoms, powers and responsibilities to local government (Wilks-Heeg 2011) not least a long-sought-after responsibility to lead on economic development (John 2014; Meegan et al. 2014). Thus within the survival narrative, the coincidence of localism with austerity creates space for councils to develop bespoke ways of 'weathering the storm' (Lowndes and McCaughie 2013). A second, more critical, narrative can also be distinguished. 'Marginalisation' downplays the adaptive capacity of councils and emphasises instead the implications of the resulting adaptations. Thus, Levitas $(2012,323)$ warns that 'all local authority services are now at risk of reduction or complete disappearance', while Taylor- Gooby $(2012,2013)$ forecasts a local government sector offering a restricted range of services, as well as increased transfers of responsibility for welfare from government to individuals and communities. Stoker $(2012,17)$ delineates a 'bleak' future in which councils become 'residual players in their communities', with the capacity only to undertake 'ameliorative programmes' focused on the needs of vulnerable groups and communities. Key to the marginalisation narrative is a storyline which describes an accelerating trend towards the privatisation, marketisation and commodification of service provision (e.g. see Jones and Stewart 2012; Levitas 2012; Taylor-Gooby 2013; Meegan et al. 2014). Here localism is viewed as an instrument for implementing budget cuts (Wilks-Heeg 2011; Lowndes and Pratchett 2011; Hastings and Matthews 2014) and it is understood as part of the larger process of state retrenchment associated with neo-liberal development, retrenchment accelerated by austerity and the responses to it (Peck 2012; Donald et al. 2014). Responsibility for economic development is viewed as an additional burden or source of vulnerability for councils with 'faddish' economic development projects potentially 'resulting in service cuts to balance budgets' (Donald et al. 2014, 6). Meegan et al. (2014) warn that the imposition of higher levels of cut on poorer locations (see also Bailey, Bramley, and Hastings 2015 for details on this) will create more divergent patterns of development.

The two storylines which underpin the literature on how local government will cope with austerity clearly contrast in important aspects. The survival narrative emphasises local government's capacity to withstand austerity via adaptations which will not challenge core aspects of its nature and purpose; indeed, it suggests that austerity presents some opportunities for creative, entrepreneurial 
activity which will allow the sector to remain a strong and significant part of the local state. Whilst the narrative is largely characterised by a positive, even optimistic, tone, there are concerns that resilience can substitute for resistance (Shaw 2012) and that the scale and speed of cuts can restrict innovation (Lowndes and Squires 2012). In the marginalisation narrative, the adaptations made by local government amount to substantial, fundamental changes which will lead to a retrenchment in the significance and centrality of local government to the citizenry, as well as in its capacity to deliver social and economic programmes which are not simply ameliorative. The narrative is overwhelmingly pessimistic: new freedoms and responsibilities are represented as a threat rather than an opportunity.

So in what ways does the empirical evidence on the sector's approach thus far to managing austerity relate to these narratives? At least some of the early evidence suggests that the survival narrative has some salience. An evidence synthesis of how councils managed austerity in the late 1970 s and early 1980s concluded that incremental rather than radical change was the result (Talbot and Talbot 2011, 69-70). Moreover, the first evidence to emerge on responses to contemporary austerity also appeared to support survival. In their case study authority, Lowndes and McCaughie (2013), found that 'resourcefulness' was leading to a creative process in which aspects of the institutional infrastructure were being made 'to serve new purposes' (11). However, while they observe that 'our overwhelming impression was of institutional resilience' (10), they also noted that their research was conducted 'when only $6 \%$ of the proposed cuts' had been made (2). Further support for survival comes from national surveys suggesting that early funding cuts were largely absorbed by so-called 'efficiency' measures (Audit Commission 2013) while a national opinion poll found that the majority of respondents thought that the quality of council services had been improved or maintained in the past five years (BBC 2013).

In contrast, there is limited evidence on the development and implementation of strategies more characteristic of marginalisation. While a survey of English Councils in 2013 found that service cuts were inevitable in all but a fifth of responding councils by 2015/2016, there was little evidence on the detail. The National Audit Office (2014) did detail service cuts in, for example, library and social care services and suggested that a substantial minority of authorities risked not being able to balance their budgets in future years. Lowndes and McCaughie describe service reductions and impacts on the care of the public realm, while early evidence from this project suggested major reductions in services for children and young people (Hastings et al. 2012). Meegan et al.'s (2014) research in Liverpool and Bristol offers perhaps the most detailed account so far of a set of service reductions which amount marginalisation, particularly in Liverpool. They argue there is evidence of a 'rolling back of state activity', a 'reconstruction' of citizen-state relations and a 'commodification' of public service delivery (156). Importantly, the studies share a common theme - no matter whether they lend support to survival or marginalisation. This was that much worse was to come, as one of Lowndes and McCaughie's interviewees said 'you ain't seen nothing yet' $(2013,3)$ (see also Hastings et al. 2012, 2013b; Meegan et al. 2014).

An aim of this paper is to examine whether there was indeed worse to come. It provides evidence on the strategies designed to tackle the budget gaps of three English case study councils over the 5-year period 2011-2016. It therefore offers the first detailed analysis of the strategies devised to manage austerity which captures a longer time period than research published to date. The paper also aims to explore the implications of these strategies by reflecting on the extent to which they concur with the survival and marginalisation narratives. By this means, the paper is able to consider what the case study evidence can tell us about possible futures for English local government.

Research approach and design 
The study design involved in-depth, mixed methods case studies of the approaches to managing austerity adopted in three English LAs. 2 A range of methods were employed to facilitate both an historic and prospective analysis of council strategies for the 5-year period 2011-2016.

The first was a set of strategic interviews with 29 senior officers including Chief Executives, members of Directorates and Heads of Service. These focused on the nature of actual and proposed strategic plans and were conducted in a staged process between the summer of 2012 to late 2013 . The second element was detailed analysis of strategic documents published by each authority between 2010 and 2013 detailing overall strategy and plans for individual service areas. The third of the case study design involved a forensic analysis of detailed budgetary information for the 5-year period $2011 / 2012$ to $2015 / 2016$ for each of the case studies. This included analysis of changes in net budgets and cost pressures across the 5 -year period using data collated from publicly available annual reports and internal documentation. Importantly, it also included analysis of the specific plans devised by each council detailing the financial savings expected from changes to services and functions - such as staff losses, service reductions, restructures or closures. These data were collated from a range of sources including budget reports and impact assessments leading to the production of a unique data base covering 1,400 detailed budget savings proposals. On an individual 'blind' basis, at least two members of the research team categorised each budget saving using a framework (Table 1) devised as a result of the strategic interviews and refined in the course of the research (see Hastings et al. 2013a); savings could be apportioned between more than one category where relevant. Discrepancies were debated and agreed internally, sometimes with reference to authority staff for clarification. The final categorisations of each authority's savings were validated in feedback sessions with senior officers. This categorisation facilitated a quantitative assessment of the balance between different aspects of each authority's strategic approach which was also capable of being triangulated with the qualitative interview and documentary data. Critically, it allows us to look ahead at plans for the coming years and to track changes over time in the balance between different means of achieving savings. We are not aware of any other studies which involve such indepth analysis of budgetary data.

The three case studies were selected on the basis of a typology of the early austerity strategies devised by councils which has been developed as the result of a telephone survey of 25 broadly representative English LAs during 2011 and 2012 (reported in Hastings et al. 2012). Subsequent engagement with the case studies suggested that their strategies had evolved considerably, so the initial distinctions are not reported here. Although only three case studies were undertaken, attempts were made to achieve a degree of regional spread and variety in relation to political control. Two authorities with high levels of deprivation were selected - as such councils were known to be experiencing the severest budget cuts, alongside a more affluent counterpart. Only unitary authorities were considered and London authorities were excluded as a separate project had this focus (see Fitzgerald and Lupton 2015). A final - and crucial - criterion was that the case studies would be prepared to work 'open book': to give the research team complete access to budgetary information and savings plans.

The case studies selected were first Newcastle City Council: an urban authority in the North East, in the most deprived quintile nationally according to the 2010 Index of Multiple Deprivation, and historically Labour-controlled although between 2004 and 2011 run by the Liberal Democrats. Second was Coventry City Council in the West Midlands region and also in the bottom quintile for deprivation. The council has historically been governed by the Labour Party, although between 2004 and 2010 it was controlled by the Conservatives. The third case study - Milton Keynes - is a more affluent urban authority in the South East (in the second least-deprived quintile) which has been governed by a Conservative minority administration since May 2012. 
The focus of this part of the paper is on explicating the strategies adopted by the case study councils and identified in Table 1, and on analysing their implications with reference to the 'survival' and 'marginalisation' narratives. Before discussing the strategies, the financial context which they relate to needs to be established. Figure 1 details the scale of the budget gap facing each case study. The figure demonstrates that all three authorities face very substantial budget gaps over the period, with an average of $7 \%$ a year or more in all three authorities and Newcastle in particular facing a consistently higher gap - averaging $10 \%$ per year. Whilst the wider literature suggests that that the early years of austerity may fit with the survival narrative, it also warns of the need for more radical steps in later austerity. In order to draw out any distinctions between the strategies of 'early' and 'later' austerity, the analysis has been structured to compare two time periods - the two years 2011/2012-2012/2013 (2011-2013) and the three years 2013/2014-2015/2016 (2013-2016). In Figure 2, the balance between the efficiency, retrenchment and investment strategies is indicated for each case study, structured using these time periods. While it demonstrates that a significant proportion of savings are or will be achieved by activities categorised as efficiencies, it also indicates a substantial shift from efficiency to retrenchment in later austerity. Arguably savings generated via efficiency measures - which remain largely invisible to service users - are suggestive of the survival narrative, whilst evidence on retrenchment strategies would support the marginalisation narrative. The remainder of this part of the paper examines each of the three headline strategies in order to explore this.

\section{Efficiency}

As indicated in Table 1, a range of activities were categorised as efficiency measures. These included restructuring and reductions of back office 'support' functions such as human resources, management 'de-layering' and increasing income generation through trading services and assets, as well as more effective debtor management. Changes to commissioning and procurement arrangements such as joint commissioning were also described as efficiencies, as were measures which involved redesigning front-line services by introducing, for example, generic working. A key criterion was that measures did not obviously compromise the level or quality of front-line services. The scale of savings achieved by these measures over the five years was substantial - in Newcastle, it was $f 84$ million, although only around half of this amount in Milton Keynes. In all three case studies, the proportion of these savings generated from 'back office' initiatives such as corporate restructuring was striking, ranging from $50 \%$ to $64 \%$ of total efficiency savings. Across the three councils, nearly $f 110$ million of savings have been generated by this means alone. In contrast, savings in frontline services generated via service consolidation or greater generic working were much smaller in scale: $£ 27$ million across the three case studies (see Hastings et al. 2013a, 24 for more details).

One of the main ways in which efficiencies had been generated was via a substantial programme of staff reductions. By 2015/2016, Newcastle will have reduced its 2010 staffing complement by 2,300 full-time equivalent (36\%), while in Coventry and Milton Keynes reductions were of the order of $22 \%$ and $18 \%$ respectively over the shorter period to 2013 Hastings et al. (2013a, 25). Clearly, staff reductions can lead to reduced services as well as deliver efficiency savings, particularly when they are in front-line services. However, the case studies were unable to distinguish between staff losses in 'back office' and 'front line' service roles, although it was clear that initial strategies tended to focus on central parts of the organisations and on management tiers and are therefore treated as efficiencies for the purpose of this analysis. Hastings et al. (2015) explores the wider impacts of staff reductions. However, it is change over time in the capacity of the councils to identify efficiency 
savings which is of particular salience. Figure 3 demonstrates the steep drops in terms of the proportion of the total savings achieved annually from efficiency measures. Officers from the three councils were keen to emphasise the difficulties of achieving efficiencies. For example, a Newcastle senior officer commented: 'We have always held on to our fundamentals, but we have got to the point that we have nowhere else to go. ... We have not scratched the surface of difficult decisions yet' while in Coventry an officer noted: 'We have to stop slicing; we've already trimmed all we can. Some services are just going to have to go'. Senior officers from Milton Keynes argued that the council had largely exhausted avenues to make significant efficiency savings: 'The real worry is what we do as we move forward ... we have taken out the easy savings'. much smaller in scale: $f 27$ million across the three case studies (see Hastings et al. 2013a, 24 for more details). One of the main ways in which efficiencies had been generated was via a substantial programme of staff reductions. By 2015/2016, Newcastle will have reduced its 2010 staffing complement by 2,300 full-time equivalent (36\%), while in Coventry and Milton Keynes reductions were of the order of $22 \%$ and $18 \%$ respectively over the shorter period to 2013 Hastings et al. (2013a, 25). Clearly, staff reductions can lead to reduced services as well as deliver efficiency savings, particularly when they are in front-line services. However, the case studies were unable to distinguish between staff losses in 'back office' and 'front line' service roles, although it was clear that initial strategies tended to focus on central parts of the organisations and on management tiers and are therefore treated as efficiencies for the purpose of this analysis. Hastings et al. (2015) explores the wider impacts of staff reductions. However, it is change over time in the capacity of the councils to identify efficiency savings which is of particular salience. Figure 3 demonstrates the steep drops in terms of the proportion of the total savings achieved annually from efficiency measures. Officers from the three councils were keen to emphasise the difficulties of achieving efficiencies. For example, a Newcastle senior officer commented: 'We have always held on to our fundamentals, but we have got to the point that we have nowhere else to go. ... We have not scratched the surface of difficult decisions yet' while in Coventry an officer noted: 'We have to stop slicing; we've already trimmed all we can. Some services are just going to have to go'. Senior officers from Milton Keynes argued that the council had largely exhausted avenues to make significant efficiency savings: 'The real worry is what we do as we move forward ... we have taken out the easy savings'. Retrenchment Retrenchment is defined as a set of changes which result in a reduced role for LAs, either in the range and level of services provided to specific client groups or in the extent of their responsibility for individual or community level wellbeing. As Figure 2 shows, retrenchment strategies were beginning to replace efficiency strategies in the three councils as the means to achieve the savings requirements of later austerity. In Figure 4, retrenchment is disaggregated into the six specific strategies identified in Table 1. It shows the balance of these strategies between the case studies as well as between the early and late austerity and demonstrates an increase in retrenchment savings between early and late austerity in all three. In Milton Keynes, almost twice as many millions were achieved in retrenchment savings in late compared to early austerity. In Coventry, the increase is almost 10-fold, although from a low base. Analysis of the annual trend (not shown) shows that there were no retrenchment savings made in Coventry in 2011/2012, but that these increased steadily over the four subsequent years. Both Newcastle and Milton Keynes saw largely steady annual increases in savings achieved by these means.

Three of the specific strategies categorised as retrenchment capture where councils have reduced the level or range of services they provide, either to citizens as a whole or to population groups. In terms of reductions in range, examples of services withdrawn included an array of services for children and young people such as out-of-school, holiday and homework clubs, mentoring and grants to youth organisations, and in the case of Milton Keynes, withdrawing from providing nursery education. In addition, arts and culture activities experienced significant withdrawals of subsidy: in Newcastle, this was designed to generate co-investment from other bodies. Finally, services designed to enhance neighbourhood liveability were withdrawn, with the deletion of neighbourhood 
warden services in Milton Keynes and Coventry. However, retaining services in diluted form tended to be preferred over service deletions. Examples included reducing the number of libraries in Newcastle, community safety projects in Milton Keynes and, in the three case studies, the frequency of grass cutting in the public realm. Interviews with senior officers suggested that they were concerned that reduced service levels would provoke protest from articulate, 'sharp elbowed' social groups or, over the longer term, lead to a loss of the support of such groups for council services.

While these examples of service reductions and withdrawals would appear to point towards Stoker's 'dynamic of decay' $(2012,15)$, the marginalisation narrative - specifically the process of residualisation - was most apparent in those strategies in which the breadth of the client groups served by particular services was narrowed. While it was clear that in relation to key 'public good' services a commitment to the principle of universalism was retained, there was a struggle ongoing to maintain this principle in practice. The Newcastle case study illuminates the challenges the councils faced. 3 Thus, in response to controversy over library closures, Newcastle interviewees and documents were clearly keen to emphasise the maintenance of universality: ' $96 \%$ of Newcastle residents still live within 1.5 miles from a library' (Newcastle City Council 2013, 29). However, indicating the necessity of focusing resources on the neediest client groups, council documentation tended to be infused with the language of 'proportionate universalism' - a model of resource allocation which guarantees a minimum level of universal service, while the scale and intensity of provision is varied with need across the social gradient (Marmot 2010). It was evident though that targeting was replacing proportionate universalism 'as cuts go deeper, it will be harder to maintain over time, particularly as we focus on core services for the more vulnerable' (senior officer, Newcastle). Changes to the provision of neighbourhood environmental services between early and later austerity exemplify this. In the early phase, a proportionate approach to street cleansing meant that all council wards were allocated to a staffing 'cluster' capturing a range of levels of need (Newcastle City Council 2013). Staff resources were allocated relative to these variations. However, a much more selective form of targeting has been developed for later austerity, with council resources focused only on 'those areas of the city which fall below acceptable standards' (ibid., 32). Indeed, a range of services were now being rationed on a much more selective basis across the case studies such as children's centres, home care, careers and other forms of advice. Figure 4 reveals that targeted approaches to service allocation had increased between early and late austerity. This is largely due the development of stricter criteria in relation to a range of social care services, such as home-based support.

The remaining three retrenchment strategies capture the idea that austerity is being managed by councils through increasing the contributions of other agencies as well as citizens to service provision and outcomes - such as appropriate levels of social care for individuals, clean streets or leisure facilities. Within the case study evidence, an undoubted, positive 'survival' narrative can be discerned in relation to how austerity has energised inter-agency collaboration as well as the development of new service models such as Newcastle's 'Health and Care City Deal' in which longterm health conditions are dealt with in an integrated manner by the council and the National Health Service (NHS). While these kinds of examples reflect wider changes in the policy context, the impetus to generate cost savings via these measures was also clear. In Newcastle, for example, the council forecast a saving of $£ 2$ million for 2015/2016 as a result of the health and care initiative. In addition to collaborative activity, there was some evidence of attempts to 'shunt' some costs to agencies deemed to have fared better in the climate of austerity, such as the NHS.

Those strategies focused on promoting additional contributions from citizens to service provision reflect the marginalisation narrative more clearly than those focused on other agencies. In the three case studies, there is a strong and growing emphasis on strategies which will change the balance of responsibility between the council as a service provider and the citizens who use these services, who 
are expected to be increasingly responsible for - in the words of one senior officer - 'delivering their own well-being'. One facet is changes to charging policies, whether by introducing charges for services which were previously 'free at the point of use', such as bulky waste collection, or by increasing pre-existing charges, to car parking for example. While the rationale is partly income generation, it is also part of wider attempts to redefine the relationship between citizens and councils.

Three main forms of citizen responsibilisation were underway in the case studies. The first - the socalled 'self-sufficiency' agenda - aims to provoke change in how citizens and councils interact by substituting generic call centres and digital communication for face-to-face contact. Coventry has embraced this approach via the development of generic call centre staff tooled with scripts to manage enquiries ranging from lost library books to impending homelessness. The second form involved the transfer of council 'assets' - such as leisure centres, libraries and community centres to local groups. Asset-based approaches to developing social and community capital have gained policy and scholarly attention in the last decade (see MacLeod and Emejulu 2014), and indeed all three councils had transferred facilities such as swimming pools to community trusts prior to 2011. However, austerity had significantly energised asset transfer programmes. More than one senior officer from Milton Keynes explained that a key driver of the council's programme was to transfer the risks and liabilities of expensive facilities from the council to other bodies. As one stated: it was to 'avoid future costs... we don't want the liability of the buildings in the long term'. Official documentation however emphasises the regenerative and social capital benefits of asset-based development. The council website, for example, explains that the goal is to put 'more control into the hands of our local communities'.

The third form of responsibilisation is the encouragement of 'civic responsibility'. Newcastle had developed a range of savings proposals which entail a shift in responsibility for preventing and addressing adult care needs from services to communities, to the things 'available in the person's own life and neighbourhood' (Newcastle City Council 2013, para. 42). In addition, a wholesale recalibration of the nature and level of street cleaning, green space and parks maintenance had been developed, reducing the staffing complement by 200 , producing savings of $£ 7.5$ million over the period 2013-2016. It is clear that responsibility for standards of cleanliness is to be passed to citizens: 'Maintaining these standards will require individuals to take personal responsibility for supporting their neighbourhoods, with the council focusing on those services which only the council can do such as street lighting' (Newcastle City Council 2013, 32).

As with some of the activities categorised as efficiency savings, there are aspects of retrenchment which have been underway within local government for a considerable period of time. Thus the diminishing role of councils in respect of direct service provision has been ongoing since the 1980s and the advent of the 'enabling local authority' with its focus on commissioning rather than delivering services. In addition, the role of councils relative to other sectors and agencies has been undergoing renegotiation since the exhortation towards partnership began in the 1980s. In the wider literature, the capacity to evolve and adapt to such contextual and policy changes is offered in support of the survival narrative (John 2014; Lowndes and McCaughie 2013). While this might suggest that retrenchment should not be understood simply as evidence in support of marginalisation, the evidence of the case studies is that the retraction of local government finance is driving a rescaling of the nature and role of local government across a range of spheres - and that marginalisation is a real and present danger. Our ongoing work which examines the consequences of these strategies for poorer communities considers the issue of residualisation in detail.

Investment 
Local government has played a significant role in economic development for more than 30 years. Moreover, LAs, particularly those responsible for urban England, have been lobbying for increased power, resources and responsibility in this sphere for some time. Indeed, both cross-party political support and practical policy change have been secured for this in the form, for instance, of City and Growth Deals which confer new freedoms in relation to investment, skills and jobs (Centre for Cities 2014). Both the interviews and budgetary analysis in Newcastle and Coventry suggested an invigoration of council activity centred on growth and associated labour market programmes. Capital and revenue spend was being more closely aligned to this agenda. In Coventry, the council's Chief Executive had taken on personal responsibility for economic development and the council had embarked on a major city centre regeneration plan, underpinned by a $£ 59$ million investment from its capital programme. In Newcastle, $£ 400$ million of capital investment, much of it focused on business growth, had been identified for the 2013-2016 period. In Milton Keynes, a contrasting emphasis was in evidence. Here the focus was on managing the impacts of the growth already underway. The council's capital budget was under significant pressure as a consequence of the need to fund the infrastructure necessary to support new housing and other forms of development, while its revenue budget was stretched by the additional service demands concomitant with population increases - in relation to schools and libraries for example. Senior officers argued strongly that austerity placed additional burdens on councils who did achieve growth. As a consequence, Milton Keynes was the first council in England to introduce a 'roof tax' designed to offset some of the costs of the infrastructure necessary to support development.

Austerity clearly drove the renewed emphasis on growth in the deprived case study councils. Concerns over longer-term fiscal resilience appeared to underpin new links being forged between strategies focused on growth and economic development and the need to reduce demand for council services. For example, as Councillor Nick Forbes, Leader of Newcastle City Council, argued: 'People in work also means fewer community tensions, fewer health and social problems, less crime, ... So creating jobs, and ensuring local people have the skills to do them, is part of our vision for a fairer city, where people rely less on public services' (Newcastle City Council 2012). Activities such as the adoption of the 'living wage' and programmes designed to promote training opportunities in growth sectors for disadvantaged groups were part of an agenda in which council resources were deployed to impact on levels of need and therefore demands on services, albeit in an indirect manner.

Finally, there was also separate strand to investment which was focused more directly on reducing demand on services and involved the realignment of some capital and revenue resources towards 'prevention' or 'invest to save' activities. For example, the three councils were investing in assisted living technology designed to promote independence and reduce pressure on care costs. Again while investment in this kind of technology pre-dates austerity - interviews suggested that much of its attractiveness lay in its capacity to save on costly forms of care, rather than enhance care as an end in itself. Both Coventry and Newcastle are also investing in strategies designed to reduce numbers of 'looked after' children and reduce future costs: Newcastle recruited five additional staff in early 2013 in an attempt to increase the rate of adoption in the city. This investment is being relied on to deliver savings of the order of $£ 3.7$ million over the period 2013-2016.

The specific saving identified with regard to looked after children was in marked contrast to the nonidentification of the level of savings anticipated for the vast majority of investment strategies. Indeed, while Figure 2 demonstrated a slight increase between early and late austerity the proportion of overall savings anticipated from investment strategies, it was clear that the majority of savings expected to accrue from investments and activities put in place in this 5 -year period were expected 'to emerge over the next 20 or so years' (senior officer, Coventry). Indeed, none of the authorities had attempted to identify the scale of savings they hoped to generate from economic 
development activity. In this sense, the centrality of investment to the strategies designed to manage austerity concurs with the view in the marginalisation narrative and noted earlier: that an augmented economic development role for councils at a time of austerity represents an additional burden on and source of vulnerability for local government. Senior officers within the case studies appeared well aware that repositioning LAs at the forefront of economic leadership was a means to localise risk and to pass it from central to local government. One argued that 'two leagues of local authorities' would result: one characterised by the capacity and operating within a context which would allow them to lead their locality out of recession and beyond austerity; a second in which capacity was too severely constrained by a context of few opportunities for growth as well as by unassailable increases in service demands.

As with both efficiency and retrenchment, there is not a simplistic correlation between investment and either the survival or the marginalisation narratives. The invigoration of the economic development role within the sector - indeed the appetite for this role - would appear to suggest adaptive capacity. Affording a central role to local government in such a key sphere could be argued to run counter to the marginalisation argument. However, the evidence also suggests that the strategies captured by investment are at the centre of a transfer of new levels of responsibility and therefore of risk to councils. In the conclusion, we focus on this issue of responsibilisation, as we suggest that a narrative of responsibilisation may be third way of framing the trajectory of English local government.

\section{Conclusion}

The framework set out and deployed in this paper to characterise the strategies used by the case study councils facilitated a robust analysis of the balance between efficiency, retrenchment and investment activities and their associated levels of saving in order to manage austerity. By differentiating the strategic mix in place for 'later' compared to the 'early' austerity, the analysis clearly identified a shift from efficiency to retrenchment in order to close budget gaps. It therefore provided clear evidence for an increasingly voiced concern that the capacity for efficiency savings within English local government was rapidly being exhausted. It also demonstrated the retraction of local government services for a range of client groups, suggesting a potential reduction in the centrality of councils to individual and community level well-being and the danger of residualisation. The relatively small scale of the savings envisaged from the various investment strategies pursued by the case study councils was also highlighted. As the analysis makes clear, as it stands, investment is not the answer to the challenges of managing austerity in the period until 2016, although it may be part of a larger-scale repositioning of what local government does and for who.

The paper has also demonstrated the value of examining these strategies in light of the narratives of survival and marginalisation. The analysis suggested that the range of efficiency savings underway could be understood as exemplifying the adaptive capacity central to the survival narrative. Yet it also identified that year-on-year efficiency measures may ultimately undermine the capacity of councils to adapt and perhaps survive. While the lack of a straightforward fit between retrenchment and marginalisation was also demonstrated, it was also clear that many of the activities classified under this heading will result in the withdrawal of a number of local government services from broad sections of the population. The principle of universalism with regard to some public good services would appear to be at stake, and a broader residualisation of council services - such that they are increasingly concentrated on low-income social groups who lack the financial capacity to access alternatives - is clearly underway. However, there is need to be alert to the danger that the 'social risk' of austerity is passed to the disadvantaged groups most reliant on public services (Asenova, Bailey, and McCann 2015) and that 'services for poor people are poor services' 
(McCormick and Philo 1995, 12). Our ongoing research considers the specific impacts of budget contraction on poor communities in some depth. The additional danger of course is that the retreat from universalism with the development of more aggressive forms of targeting alongside the decline in the maintenance of the public realm may well fuel a loss of support for council services (and taxes) from better off social groups - further driving and embedding the process of marginalisation.

Of the three strategies distinguished in the framework, investment fitted least well with the survival and marginalisation narratives. Thus there was evidence of councils seeking out and adapting to new roles and responsibilities with respect to 'prevention' and economic growth. However, the analysis also suggested the strategies devised under this rubric did not help the councils cope with cuts in either early or later austerity. Indeed, in Milton Keynes, managing the costs of growth was an additional financial pressure and source of risk for the council. For this reason, these investment roles might be viewed as just another burden on local government. Indeed, the set of activities captured by investment, as well as some of those classified under the other two headings, suggest the need for a third narrative - responsibilisation - to complement the narratives of marginalisation and survival.

'Responsibilisation' is usually understood as a neo-liberal technology of government in which the purpose of the state is the governance of 'conduct' (Foucault 1991) - specifically to work in ways that ensure that a sense of responsibility for tackling social problems and achieving desirable outcomes is transferred from state institutions to citizens (Lemke 2001). This conception of responsibilisation is apparent in the case studies with respect to the transfer of assets such as sports centres and community halls to community organisations, as well as in relation to the expectation that citizen action will become more central to maintaining environmental cleanliness, caring for elderly neighbours and coproducing health outcomes. However, the concept might also be useful for understanding how central/local government relations are being reshaped as a result of the intersection between the austerity and localism agendas. As we argue in the introduction to this symposium (Bailey, Bramley, and Hastings 2015), localism is clearly a process by which some further responsibilities, and their associated risks, are transferred to the local government sector, with the ambition that some, but by no means all, of these responsibilities are then devolved further to citizens. The ways in which austerity is also being deployed to this end is probably less apparent. Thus, the nature of the decisions taken by central government on how to manage national-level fiscal pressures can be seen to be part of a project to 'shape the conduct' (Rose 1999) of local government by requiring it to behave more entrepreneurially; to take on more responsibility for economic growth and the distribution of benefits; and to take on new risks in relation both to the demands placed on services such as social care and for balancing budgets. Allied to this is the additional responsibility conferred on the sector if its services become increasingly centred on lowincome groups with few choices. A break with universalism carries the danger that a sense of shared responsibility for community- and individual-level outcomes might be compromised, and that the redistributive capacity of local government could eventually be undermined. It also suggests an intensification of responsibility for the poorest fraction of the population on the sector. Taken together, the three narratives suggest that local government may well survive, but that it will have to change to a very substantial extent. The terms of its survival would appear that it becomes both more marginalised and, paradoxically, responsibilised.

Disclosure statement

No potential conflict of interest was reported by the authors. 
Notes on contributors

Annette Hastings is professor of urban studies at the School of Social and Political Sciences, University of Glasgow. Her recent research deals with the nature and causes of urban inequality, focusing on how local services can contribute to maintaining as well as tackling inequality. She is the author, with Peter Matthews, of 'Bourdieu and the Big Society: empowering the powerful in public service provision?' in Policy and Politics, 2014.

Nick Bailey is professor of urban studies at the School of Social and Political Sciences, University of Glasgow. He is interested in the analysis of poverty and inequality, and in neighbourhoods and spatial inequalities. He is the author, with K. Besemer, G. Bramley, and M. Livingston, of 'How neighbourhood social mix shapes access to resources from social networks and from services' in Housing Studies (forthcoming).

Kirsten Besemer is a research associate at the Institute for Social Policy, Housing, Environment and Real Estate in the School of Energy, Geosciences, Infrastructure and Society at Heriot-Watt University in Edinburgh. Her research has focused on poverty and social exclusion, with particular reference to local services, housing/homelessness and financial exclusion, and on equalities issues and neighbourhoods. She is the author, with Peter Matthews, of "The "Pink Pound" in the "Gaybourhood"? Neighbourhood deprivation and sexual orientation in Scotland' in Housing, Theory and Society, 2015.

Glen Bramley is professor of urban studies at the Institute for Social Policy, Housing, Environment and Real Estate in the School of Energy, Geosciences, Infrastructure and Society at Heriot-Watt University in Edinburgh. His recent research has focused on planning for new housing, modelling the impact of planning on the housing market, housing need and affordability, low-cost home ownership, poverty, deprivation and the funding and outcomes local services. He is the author, with D. Watkins, of 'Housebuilding, demographic change and affordability as outcomes of local planning decisions: exploring interactions using a sub-regional model of housing markets in England' in Progress in Planning, 2015

Maria Gannon is a research associate in urban studies in the School of Social and Political Sciences at the University of Glasgow. Her research focuses on the nature and extent of poverty and inequality and the public's attitude towards vulnerable groups. She is the author, with N. Bailey, of 'Attitudes to the "necessities of life": would an independent Scotland set a different poverty standard to the rest of the UK?' in Social Policy and Society, 13(3). 
Notes

1. This paper reports some of the findings from the Joseph Rowntree Foundation funded project Serving Deprived Communities in a Recession.

2. A Scottish case study is also being conducted as part of the bigger project.

3. These were tackled in the context of a council-sponsored Fairness Commission which aimed to be informed by wider considerations of fairness: http://www.ncl.ac.uk/socialrenewal/ engagement/fairnesscommission/documents/fairnessreport.pdf

4. http://www.milton-keynes.gov.uk/leisure-tourism-and-culture/sport-leisure-and-community/ background-info

5. A 'roof tax' or infrastructure tariff is levied on developers and is designed to cover towards $75 \%$ of the costs of the infrastructure necessary to support development, with the shortfall theoretically made up by central government grants provided in support of growth, including the new grant - the New Homes Bonus.

\section{References}

Asenova, D., S. Bailey, and C. McCann. 2015. "Managing Muncipal Austerity: Mitigation of Social Risks." Local Government Studies 41 (1): 1-19. doi:10.1080/

03003930.2014 .919268$.

Audit Commission. 2013. Tough Times 2013: Councils' Response to Financial

Challenges from 2010/11 to 2013/14. London: TSO.

Bailey, N., G. Bramley, and A. Hastings. 2015. "Local Responses to 'Austerity'." Local

Government Studies.

BBC. 2013. "Public Service Cuts: Did We Notice?" http://www.bbc.co.uk/news/uk-

24454006

Coping with the Cuts? 619

Bunt. L, Harris M., and Westlake, S. 2010. Schumpeter Comes to Whitehall: Cuts and Innovation in Public Services. London: NESTA.

Centre for Cities. 2014. Cities Outlook 2014. London: Centre for Cities.

Donald, B., A. Glasmeier, M. Gray, and L. Lobao. 2014. "Austerity in the City: Economic

Crisis and Urban Service Decline?" Cambridge Journal of Regions, Economy and

Society 7: 3-15. doi:10.1093/cjres/rst040.

Fitzgerald, A., and R. Lupton. 2015. "The Limits to Resilience: The Impact of Local

Government Spending Cuts in London." Local Government Studies.

Foucault, M. 1991. "Governmentality." In The Foucault Effect: Studies in

Governmentality, edited by G. Burchell, C. Gordon, and P. Miller, 87-104. Chicago,

IL: University of Chicago Press.

Hastings, A., Bailey, N., Bramley, G., Gannon, M., and Watkins, D. 2015. The Cost of the

Cuts: The Impact on Local Government and Poorer Communities. York: JRF. http://

www.jrf.org.uk/publications/cost-cuts-impact-local-government-and-poorer-communities

Hastings, A., G. Bramley, N. Bailey, K. Besemer, and D. Watkins. 2013a. Coping with the

Cuts? Local Government and Poorer Communities. York: Joseph Rowntree

Foundation.

Hastings, A., G. Bramley, N. Bailey, K. Besemer, and D. Watkins. 2013b. "Coping with

the Cuts? Local Government and Poorer Communities." Main Report University of

Glasgow. http://eprints.gla.ac.uk/94599/

Hastings, A., G. Bramley, N. Bailey, and D. Watkins. 2012. Serving Deprived

Communities in a Recession. York: Joseph Rowntree Foundation.

Hastings, A., and P. Matthews. 2014. "Bourdieu and the Big Society: Empowering the

Powerful in Public Service Provision?" Policy \& Politics. http://dx.doi.org.ezproxy.lib.

gla.ac.uk/10.1332/030557314X14080105693951 
John, P. 2014. "The Great Survivor: The Persistence and Resilience of English Local Government." Local Government Studies 40 (5): 687-704. doi:10.1080/ 03003930.2014 .891984$.

Jones, G., and J. Stewart. 2012. "Local Government: The Past, the Present and the Future." Public Policy and Administration 27 (4): 346-367. doi:10.1177/ 0952076712439979.

Lemke, T. 2001. "'The birth of bio-politics': Michel Foucault's lecture at the Collège de France on neo-liberal governmentality." Economy and Society 30 (2): 190-207. doi:10.1080/03085140120042271.

Levitas, R. 2012. "The Just's Umbrella: Austerity and the Big Society in Coalition Policy and Beyond." Critical Social Policy 32 (3): 320-342. doi:10.1177/0261018312444408. Lowndes, V., and K. McCaughie. 2013. "Weathering the Perfect Storm? Austerity and Institutional Resilience in Local Government." Policy \& Politics 41: 533-549.

doi:10.1332/030557312X655747.

Lowndes, V., and L. Pratchett. 2011. "Local Governance under the Coalition Government: Austerity, Localism and the 'Big Society'." Local Government Studies 38 (1): 21-40. Lowndes, V., and S. Squires. 2012. "Cuts, Collaboration and Creativity." Public Money \& Management 32 (6): 401-408. doi:10.1080/09540962.2012.728779.

MacLeod, M. A., and A. Emejulu. 2014. "Neoliberalism with a Community Face? A Critical Analysis of Asset-Based Community Development in Scotland." Journal of Community Practice 22 (4): 430-450.

Marmot, M. 2010. Fair Society, Healthy Lives. Strategic Review of Health Inequalities. London: HMSO Publications.

McCormick, J., and C. Philo. 1995. "Where Is Poverty? the Hidden Geography of Poverty in the United Kingdom." In Off the Map: The Social Geography of Poverty in the UK, edited by C. Philo, 1-22. London: CPAG.

620 A. Hastings et al.

Meegan, R. A., P. Kennett, G. Jones, and J. Croft. 2014. "Global Economic Crisis, Austerity and Neoliberal Urban Governance in England." Cambridge Journal of Regions, Economy and Society 7 (1): 137-153. doi:10.1093/cjres/rst033.

National Audit Office. 2014. Financial Sustainability of Local Authorities 2014. Report by the Comptroller and Auditor General. London: DCLG.

Newcastle City Council. 2012. "Newcastle - A Working City. Promoting Opportunity in Tough Times." http://www.newcastle.gov.uk/your-council-and-democracy/consultationsand-community-engagement/newcastle-a-working-city

Newcastle City Council. 2013. "Fair Choices for Tough Times: Newcastle City Council's Budget Proposals 2013-2016." http://www.newcastle.gov.uk/sites/drupalncc.newcastle. gov.uk/files/wwwfileroot/your-council/budget_and_annual_report/fair_choices_tough _times_-_final.pdf

Peck, J. 2012. "Austerity Urbanism." City: Analysis of Urban Trends, Culture, Theory, Policy Action 16 (6): 626-655. doi:10.1080/13604813.2012.734071.

Rose, N. 1999. Powers of Freedom: Reframing Political Thought. Cambridge: Cambridge University Press.

Shaw, K. 2012. "The Rise of the Resilient Local Authority?" Local Government Studies 38 (3): 281-300. doi:10.1080/03003930.2011.642869.

Stoker, G. 2012. "The Political Environment and Localism: What Future?" In Housing 2020: Six Views of the Future for Housing Associations, edited by S. Graham, 7-22.

Coventry: Orbit Group.

Talbot, C., and Talbot, C. 2011. "Local Government Strategies in an Age of Austerity." In Redefining Local Government, edited by C. Oyarce. London: Accenture.

Taylor-Gooby, P. 2012. "Root and Branch Restructuring to Achieve Major Cuts: The 
Social Policy Programme of the 2010 UK Coalition Government." Social Policy \& Administration 46 (1): 61-82. doi:10.1111/spol.2012.46.issue-1.

Taylor-Gooby, P. 2013. The Double Crisis of the Welfare State and What We Can Do About It. Basingstoke: Palgrave Macmillan.

Wilks-Heeg, S. 2011. "You Can't Play Politics with People's Jobs and People's Services': Localism and the Politics of Local Government Finance." Local Economy 26 (8):

635-651. 
